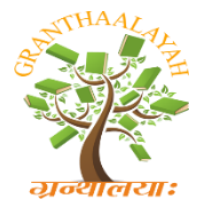

\author{
INTERNATIONAL JOURNAL OF RESEARCH - \\ GRANTHAALAYAH \\ A knowledge Repository
}

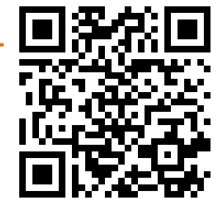

Social

\title{
VOCABULARY DEVELOPMENT VIA WORD ASSOCIATION AMONG FRESHMAN STUDENTS IN THE COLLEGE OF ARTS \& COMMUNICATION OF UNIVERSITY OF EASTERN PHILIPPINES
}

\author{
Anavil Lou G. Balanon *1 \\ ${ }^{* 1}$ Languages \& Communication Department, College of Arts \& Communication, University of \\ Eastern Philippines, Catarman, Northern Samar, Philippines
}

\begin{abstract}
Responses in terms of semantic association including paradigmatic and syntagmatic association, non semantic association including clang (phonological-related) and orthographical (spellingrelated) association and random or other types of association of the freshman students in the College of Arts and Communication, University of Eastern Philippines was determined in this study. Secondly, this finds out whether AB LLT students which are the screened students in the college of arts and communication produce other types of responses besides the commonly known semantic responses.

The instrument and stimuli was patterned after the study of Lan Wang of Indiana University of Pennsylvania, USA., entitled Word Association: Second Language Vocabulary Acquisition and Instruction. Modification was just made according to the locale of the study.

Overall result of this study, the AB LLT respondents produced more semantic associations than the BSCrim, BSDevCom, ABPolSci, BSCD, ABPubAd and ABSocio respondents while the BSCrim, BSDevCom, ABPolSci, BSCD, ABPubAd and ABSocio respondents produced more nonsemantic and random or other types of associations than the AB LLT respondents.
\end{abstract}

Keywords: Vocabulary Development; Word Association; Semantic Responses.

Cite This Article: Anavil Lou G. Balanon. (2019). "VOCABULARY DEVELOPMENT VIA WORD ASSOCIATION AMONG FRESHMAN STUDENTS IN THE COLLEGE OF ARTS \& COMMUNICATION OF UNIVERSITY OF EASTERN PHILIPPINES." International Journal of Research - Granthaalayah, 7(6), 84-92. 10.29121/granthaalayah.v7.i6.2019.762.

\section{Introduction}

Most wonderful of all are words, and how they [relate] one with another.

O. Henry, as modified by semantician

An article in the Philippine Daily Inquirer revealed that even job-seekers could hardly get their jobs because of low English proficiency. Jose Rolan Moya, of the Employers' Confederation of the Philippines said that the low English proficiency among job-seekers has been a huge problem 
for the hiring companies, notably call centers. The vacancies have been available for quite some time but applications almost always fail in the language skills department.

Learning a language includes the agreed upon meanings of certain strings of sounds and learning how to combine these meaningful units into larger units that also convey meaning. Without vocabulary, one cannot express thought and communicate with others either textually or orally (Lenelt, 1989). Vocabulary is also critical in comprehension because lexical information helps determine syntactical relationships (Altman, 1990, cited in Gass \& Selinker, 2001)

Word association is one means of measuring vocabulary development because it signifies knowledge of lexicon. Thus, poor performance in English which is manifested in several ways as in correct grammar, lack of fluency in the language, poor reading comprehension skills, lack of interest in reading and poor writing be enhanced.

So, this study aims at finding out, first, whether the $1^{\text {st }}$ year students of the college of arts and communication produce other types of responses. Second, the study aims to find out whether AB LLT students produce other types of responses besides the commonly known semantic responses. Hence, the result of this study would benefit the following: primarily to the language teachers, they will be enlightened with the various pointers in the improvement of their teaching and their students through the use of word association in vocabulary development. The teachers would also improve themselves not only in teaching their students but also in becoming more competent users of the language in their everyday living. Next, to the teacher-education institutions, this study would serve as an avenue towards attaining quality education. It is expected to provide specific insights of the kind of strategy and intervention used in the classroom that would increase the students' learning ability. An association theory is used in this study which stems from behaviorism and states that concepts are learned by simple, reinforced connections between a stimulus and a desired response. When an organism makes connections between a stimulus (e.g., a bell ringing) and a response (e.g., pressing a lever which ultimately lead to a reward), it is making an association.

An association theory looks for latent relationships, the covert links that words have with other words, images and thoughts. According to C. G. Jung.

\section{Materials and Methods}

\section{Method}

\section{Respondents}

A total of two hundred four $(\mathrm{N}=204)$ respondents from the College of Arts \& Communication, University of Eastern Philippines participated in this quasi experiment. 
Table 1:

\begin{tabular}{|l|l|l|l|l|l|l|}
\hline \multirow{2}{*}{ Course } & \multirow{2}{*}{ Age } & \multicolumn{2}{|c|}{ Gender } & \multicolumn{2}{c|}{ English Placement Result } & \multirow{2}{*}{ Total Number } \\
\cline { 3 - 6 } & & Male & Female & English 111 & English Plus & Totaln \\
\hline Bscrim & $15-20$ & 8 & 24 & 0 & 32 & 32 \\
\hline Bsdevcom & $15-25$ & 8 & 27 & 22 & 13 & 35 \\
\hline AB LLT & $15-20$ & 6 & 28 & 34 & 0 & 34 \\
\hline Abpolsci & $15-20$ & 16 & 14 & 24 & 6 & 30 \\
\hline BSCD & $15-25$ & 9 & 20 & 20 & 9 & 29 \\
\hline Abpubad & $15-25$ & 8 & 13 & 16 & 5 & 21 \\
\hline Absocio & $15-20$ & 7 & 16 & 14 & 9 & 23 \\
\hline TOTAL & \multicolumn{7}{|l}{} & 204 \\
\hline
\end{tabular}

The table above shows that age of the respondents varies from 15-25. The gender of the BScrim respondents were eight for male and 24 were female, BSDev Com shows that 8 were male and 27 were female, for ABLLT 6 were male and 28 were female, with the ABPolSci there were 16 male and 14 female, with the BSCD 9 were male and 20 were female, ABPubAd shows that 8 were male and 13 female and lastly for the ABSocio 7 were male and 16 were female. The result of their English placement test shows that majority of the respondents passed the placement exam except for BScrim where they were all under English plus. In addition, they displayed a range of 2 to 9on self rating of English proficiency, with 1 representing minimum proficiency and 10 representing native-like proficiency. They all started learning English at age of 6 years old and their average period of learning was ten years.

\section{Instrument and Stimuli}

The instrument and stimuli was patterned after the study of Lan Wang of Indiana University of Pennsylvania, USA., entitled Word Association: Second Language Vocabulary Acquisition and Instruction. Modification was just made according to the locale of the study. A total of 49 stimuli (see Appendix 1), including one practice word (doctor) and 48 experimental words, were employed in this experiment. Each participant was asked to write down their first word response when seeing the stimulus word. Each stimulus word was presented for about 10 seconds so that the participants could have enough time to write down the first word which they associated with the stimulus.

The stimuli were set of common words. The main criteria for choosing these stimulus words is that, first, the stimuli were common words that the participants would be familiar with; second, the stimuli would stimulate the participants to associate without difficulty. Also, some words were purposely changed for a better understanding or association of the word.

\section{Procedure}

The experiment was conducted in different classes and upon approval of the teachers handling classes to the participants of this study. The researcher first explained the purpose of this study to the participants and then ask them to fill out the demographic information (see Appendix 2) before the experiment. On the experiment sheet a space was provided for the one practice word, and each response word with corresponding numbers so that the participants could write down their responses with the help of the numbers (see Appendix 3). 
The 49 stimuli were presented by the researcher using 49 white flashcards. The stimulus was printed in the middle of each using bold faced 100 font type. During the experiment, the researcher presented the stimuli one by one holding each flashcard for about 10 seconds in order to give the participants time to write down their responses. To help the participants be familiar with the process and guide them to respond in an appropriate way, the directions and one word were prepared for the participants to practice before the experiment started. The experiment lasted about 15 to 20 minutes.

\section{Data Collection and Analysis}

Dr. John Curry, Professor of Educational Research, North Texas State University provided his "rule of thumb" on ideal sample size, that is, for 100 to 1000 population, $10 \%$ is applicable.

L. R. Gay suggests $10 \%$ of large population and $20 \%$ of small populations as minimum. The researcher applied the rule according to Dr. John Curry for the BS Criminology course since there are $3151^{\text {st }}$ year students enrolled for this semester and for the AB LLT, AB Pub Ad, AB Socio, AB Pol Sci, BS Dev. Com and BS CD course the researcher applied not just the minimum $20 \%$ of the total population for every 100 below population but instead $50 \%$ to get a better and reliable result.

BS Criminology has 315 students; AB LLT has 77; AB Pub Ad has 51; AB Socio has 46; AB Pol Sci has 60; BS Dev.Com has 71 and BS CD has 58 total number of population. Computing the $10 \%$ for BSCrim and $50 \%$ for the rest of the course the researcher was able to draw a total sample of 204 .

The word association responses by the 204 participants were classified into three type: 1) semantic association2) nonsemantic associationsand 3) random or other types of associations. Take the stimulussink as an example, responses such as boat, kitchen, dish wash, water to the stimulus sink were categorized as semantic type of association; however, if the responding words were think, ink, they were labeled as the non semantic type of response; the third type, random or other association words, were those that had no connection with the stimulus word. For instance, it is hard to figure out what the connection was between the responding word tournament, internet, and obstacle to the stimulus sink.

Because of the different numbers of respondents in the sevencourses, the total number ofthe responses is different. The BSCrim respondents produced 1231 responses,BSDevCom produced 1389 responses, AB LLT produced 1632 responses, ABPolSci produced 1239 responses, BSCD produced 1102 responses, ABPubAd produced 908 responses and ABSocio produced 912 responses.

\section{Results and Discussions}

The statistical results indicated that although the total number of responses produced by the BSCrim, BSDevCom, ABPolSci, BSCD, ABPubAd, ABSocio courses was larger than the AB LLT course, the AB LLT produced more semantic associations and fewer nonsemantic and random or other types of associations than the BSCrim, BSDevCom, ABPolSci, BSCD, ABPubAd, ABSocio courses. 


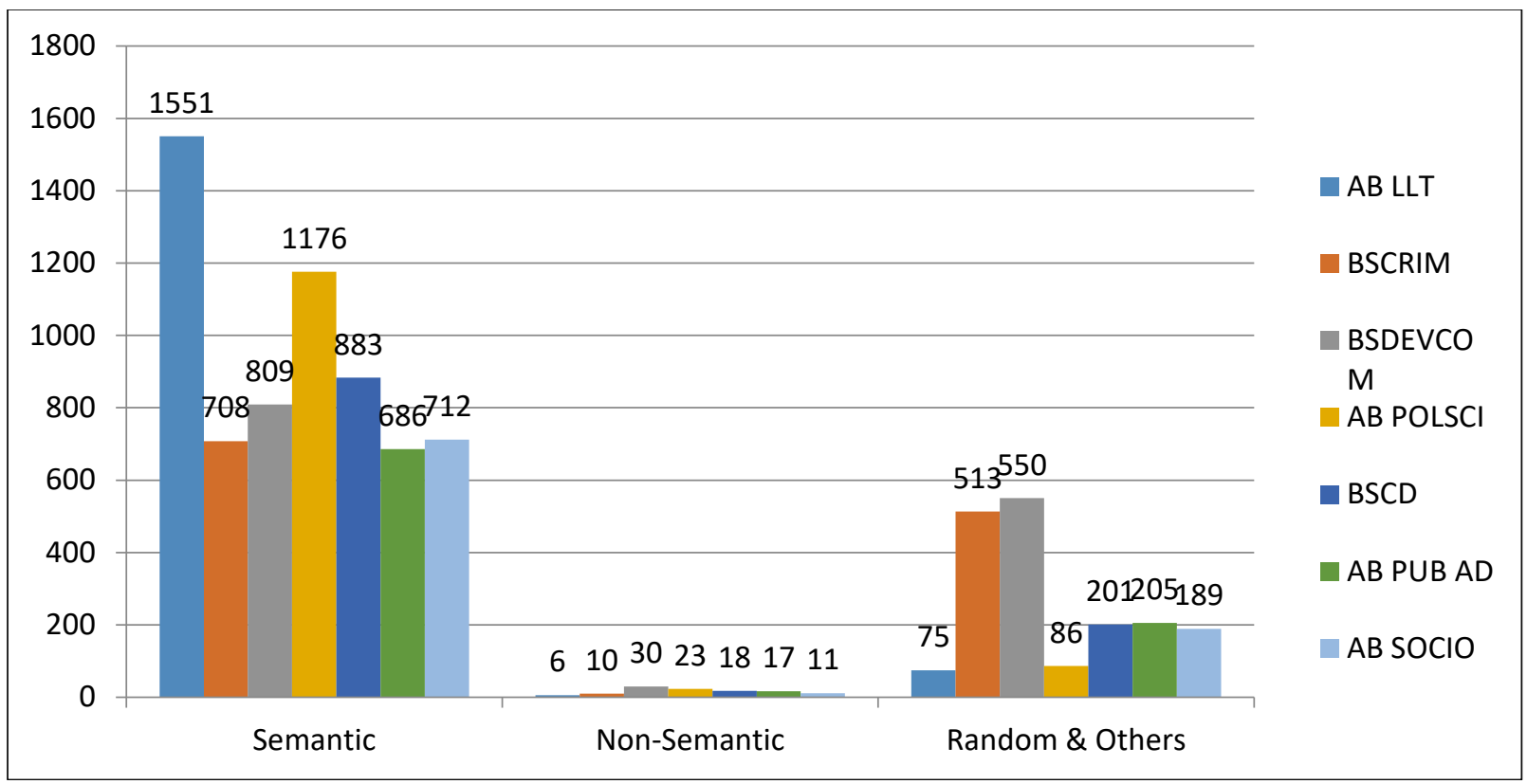

Figure 1: Graph of word association types by AB LLT, BSCRIM, BSDEVCOM, ABPOLSCI, BSCD, ABPUBAD and ABSOCIO courses

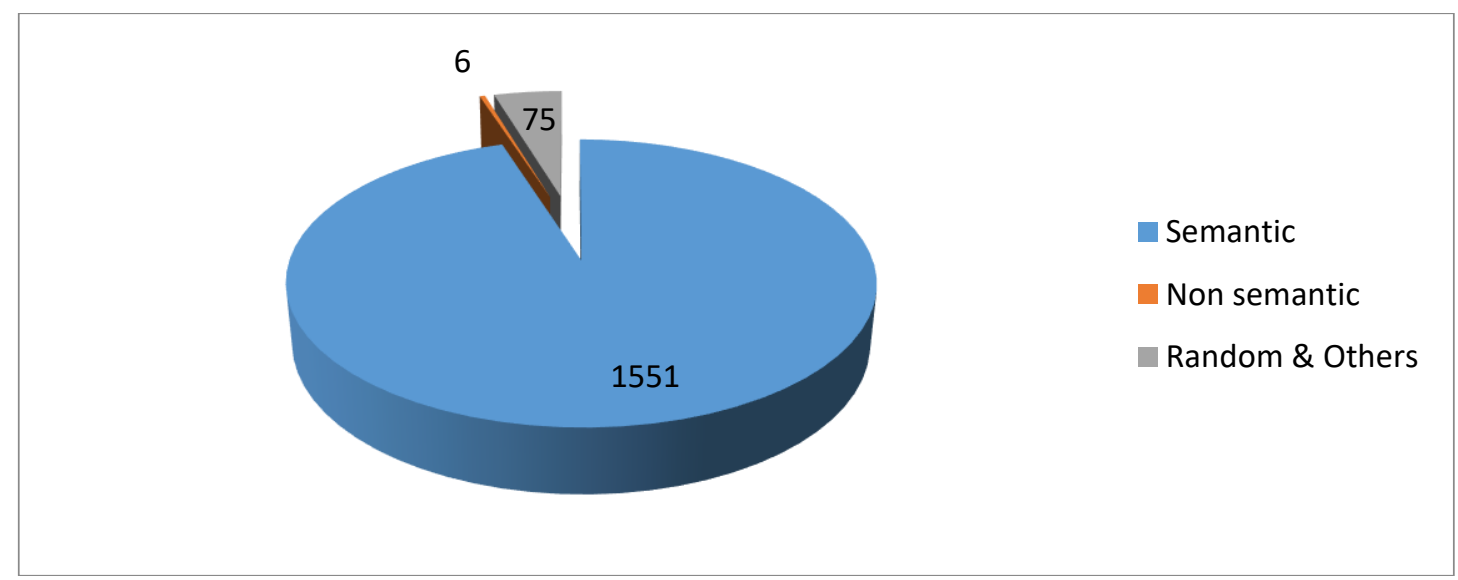

Figure 2: AB LLT 's response types

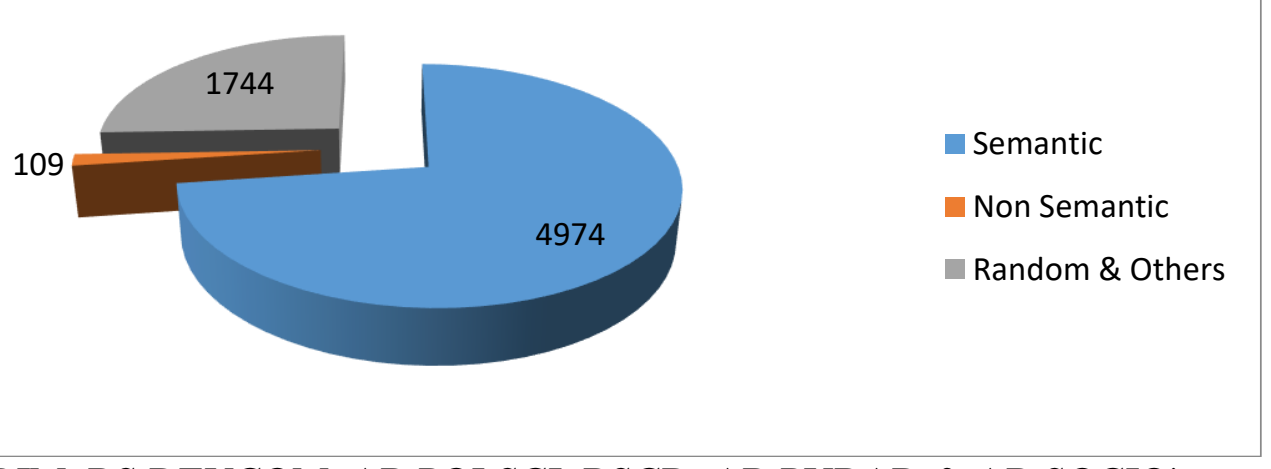

Figure 3: BSCRIM, BS DEVCOM, AB POLSCI, BSCD, AB PUBAD \& AB SOCIO's response types 
On the whole, both the BSCrim, BSDevCom, ABPolSci, BSCD, ABPubAd and ABSocio courses and the AB LLT course responded mainly with semantic associations. First, BSCrim, BSDevCom, ABPolSci, BSCD, ABPubAd, ABSocio courses produced 4974 semantic associations out of the total of 6781 while the AB LLT course responded with 1512 semantic associations out of the total of 1632. Second, the portion of nonsemantic types of responses by both BSCrim, BSDevCom, ABPolSci, BSCD, ABPubAd, ABSocio courses and AB LLT were moderately small but for the random and other types of responses from the BSCrim, BSDevCom, ABPolSci, BSCD, ABPubAd, ABSocio courses were moderately higher than the AB LLT course.

Evidently, based on the respondents responses on their self rated language proficiency scores and the result of their English placement test result, the researcher could easily notice that the vocabulary size seemed to be small for the less advanced learners.

Additionally, if the vocabulary storage is not large enough, BSCrim, BSDevCom, ABPolSci, $\mathrm{BSCD}, \mathrm{ABPubAd}$ and ABSocio's responses then tend to produce fewer associations and more random and nonsemantic associations. In other words, BSCrim, BSDevCom, ABPolSci, BSCD, ABPubAd and ABSocio's respondents were able to produce semantic associations if the stimulus is common or familiar word to them; in contrast, once the stimulus is unfamiliar or less frequently used, or the meaning of the stimulus is unknown, they may produce other types of responses. For example, the word kiwi could be an uncommon word to some BSCrim, BSDevCom, ABPolSci, BSCD, ABPubAd and ABSocio respondents; some responses to this word were animal, black or even people, indicating that these BSCrim, BSDevCom, ABPolSci, BSCD, ABPubAd and ABSocio respondents did not know the exact meaning of kiwi. This finding supports the belief that word association is closely connected with learners' vocabulary size and language proficiency (Schmitt \&58 TESL Reporter Meara, 1997) as well as their word knowledge and the frequency of the word use (Greidanus \& Nienhui, 2001). That is, the more extensive vocabulary size and the higher proficiency the learner has, the more semantic association he or she produces.

\section{Conclusions and Recommendations}

Overall result of this study, the AB LLT respondents produced more semantic associations than the BSCrim, BSDevCom, ABPolSci, BSCD, ABPubAd and ABSocio respondents while the BSCrim, BSDevCom, ABPolSci, BSCD, ABPubAd and ABSocio respondents produced more nonsemantic and random or other types of associations than the AB LLT respondents.

The study clearly demonstrates that lower level L2 learners gave fewer semantic but more nonsemantic and random associations than the higher level L2 learners. Unfamiliar words evoke nonsemantic and/or random associations by both the BSCrim, BSDevCom, ABPolSci, BSCD, ABPubAd and ABSocio respondents and the AB LLT respondents.

Certainly, this study has some limitations such as the choice of the stimuli and the experimental environment (BSCrim, BSDevCom, ABPolSci, BSCD, ABPubAd and ABSocio respondents and the AB LLT respondents were tested together). Due to these factors, the results might be inaccurate to some degree. However, the major findings confirm that L2 learners are in the continuum process of vocabulary development. That is, L2 learners have a word-knowledge continuum which L1 
learners do not because they acquire a word mainly through meaning. However, the difference can be lessened over time with the increased proficiency of L2 learners (Coady, 1993).

\section{Recommendations}

In the light of this study's result, the following recommendations are formulated:

1) Instructors need to pay attention to the meaning instruction of L2 vocabulary. In other words, teaching words in isolation is not effective; teaching word form and word meaning together is appropriate and crucial in L2 vocabulary acquisition.

2) When teaching vocabulary, instructors should teach the form, meaning, and pronunciation of a word together as a package rather than teaching only one aspect of the word. Activities such as recalling the form of the new word as well as listening to and reading aloud the new word might be helpful.

3) Low-proficiency learners may store words in memory on the basis of sound and spelling rather than by association of meaning due to the limited extent of their vocabulary, teaching the relationship of sound and spelling seems important and necessary at the beginning level. Then, gradually teachers need to help learners improve other aspects of word knowledge with the increase of their language English proficiency.

4) Instructors should realize the differences and determine appropriate strategies to meet the needs of the learners at different levels. To be specific, if learners tend to produce associations depending on the form of words, instructors should avoid teaching words with similar forms. Further, instructors need to be aware that for lower level learners in particular, teaching new words with similar or closely related meanings together can be problematic or dangerous because vocabulary taught in semantic groups may confuse learners and hinder their vocabulary retention.

5) Further, a vocabulary enrichment program/activities should be proposed to developed vocabulary skills among students.

\section{Acknowledgements}

The author wish to thank the University of Eastern Philippines Graduate Studies, the College of Arts and Communication, and the UEP Administration for the support extended in the completion of this study.

\section{Appendices}

\section{Appendix 1}

\section{Stimuli of Word Association Experiment}

Part I: Words for practicing: 1) doctor

Part II: Words for experiment:

$\begin{array}{llllllll}\text { Pan } & \text { dress } & \text { weather } & \text { bridge } & \text { kiwi } & \text { sheet } & \text { pillow } & \text { food } \\ \text { sink } & \text { chimney } & \text { nest sword } & \text { carpark frog } & \text { barrel } & \text { fork } & \text { basketball } \\ \text { principal flue } & \text { mouse } & \text { industrious light } & \text { jury } & \text { dessert } & \text { bug } \\ \text { web } & \text { sleep } & \text { soldier } & \text { hungry } & \text { commit } & \text { net } & \text { parking } & \text { butterfly } \\ \text { cheers } & \text { fish } & \text { needle } & \text { sandwich } & \text { horse } & \text { sauce } & \text { bitter } & \text { connect } \\ \text { quiet } & \text { cough } & \text { vote } & \text { calcium } & \text { kitchen } & \text { noise } & \text { camp } & \end{array}$




\section{Appendix 2}

\section{Demographic Information of the participants}

Put check marks or write down your answer in the spaces provided below.

1) Current Degree Program:

2) Gender: male Female

3) Age:

4) At what age did you start learning English?

5) How long did you study English in school and college? (years/months)

6) If you have been to other English -speaking countries, how long did you stay there? (year/month)

7) Rate your own English proficiency on the following scale by circling the numbers:

\begin{tabular}{|c|c|c|c|c|c|c|c|c|c|c|}
\hline Speaking & 1 & 2 & 3 & 4 & 5 & 6 & 7 & 8 & 9 & 10 \\
\hline Listening & 1 & 2 & 3 & 4 & 5 & 6 & 7 & 8 & 9 & 10 \\
\hline Reading & 1 & 2 & 3 & 4 & 5 & 6 & 7 & 8 & 9 & 10 \\
\hline Writing & 1 & 2 & 3 & 4 & 5 & 6 & 7 & 8 & 9 & 10 \\
\hline
\end{tabular}

\section{Appendix 3}

\section{WORD ASSOCIATION RESPONDING SHEET}

Directions: Please write down the first word that comes into your mind in the given spaces one by one when you read the presented word. The researcher will leave 10 seconds after presenting each word so that you can write down what comes into your mind. The first 3 are for your practice the procedure. The real experiment will consist of 48 words.

Practice: $\quad 1$.

Now the experiment begins:

\begin{tabular}{|l|l|l|l|l|}
\hline 1. & 2. & 3. & 4. & 5. \\
\hline 6. & 7. & 8. & 9. & 10. \\
\hline 11. & 12. & 13. & 14. & 15. \\
\hline 16. & 17. & 18. & 19. & 20. \\
\hline 21. & 22. & 23. & 24. & 25. \\
\hline 26. & 27. & 28. & 29. & 30. \\
\hline 31. & 32. & 33. & 34. & 35. \\
\hline 36. & 37. & 38. & 39. & 40. \\
\hline 41. & 42. & 43. & 44. & 45. \\
\hline 46. & 47. & 48. & \multicolumn{3}{|l}{} \\
\cline { 1 - 3 } & \multicolumn{4}{|l}{}
\end{tabular}

\section{References}

[1] Altman, G. (1990). Cognitive models of speech processing: An introduction. In G. Altman (Ed.), Cognitive models of speech processing: Psycholinguistic and computational perspectives (pp.123). Cambridge, MA: MIT Press. 
[2] Coady, J. (1993). Research on ESL/EFL vocabulary acquisition: Putting it in context. In T. Huckin, M. Haynes, \& J. Coady (Eds.), Second language reading and vocabulary learning (pp. 3-23). Norwood, NJ: Ablex.

[3] Gass, S., \& Selinker, L. (2001). Second language acquisition: An introduction course.

[4] Greidanus, T., \& Nienhuis, L. (2001). Testing the quality of word knowledge in a second language by means of word associations: Types of distracters and types of associations. The Modern Language Journal, 85(4), 567-577.

[5] Levelt, W. J. M (1989). Speaking: From intention to articulation. Cambridge, MA: MIT Press.

[6] Meara, P. (1978). Learners' word association in French. International Studies Bulletin (Utrech) 3(2), 192-211.

[7] Nation, I. S. P. (1990). Teaching and learning vocabulary. New York: Newbury House.

[8] Schmitt, N., \& Meara, P. (1997). Researching vocabulary through a word knowledge framework: Word association and verb suffixes. Studies in Second Language Acquisition, 19, 17-36.

[9] Tinkham, T. (1993). The effects of semantic clustering on the learning of second language vocabulary. System, 21, 371-380.

[10] Wang, Lan. Word Association: Second Language Vocabulary Acquisition and Instruction. TESL 41-66

\footnotetext{
*Corresponding author.

E-mail address: anvillou_13ave@yahoo.com
} 